\title{
La fotografía, entre la memoria y la narrativa
}

\section{Photography, between memory and narrative}

DOI: $10.46932 /$ sfjdv3n1-030

Received in: Dec 30st, 2021

Accepted in: Jan 1th, 2022

\author{
Dr. Marco Antonio Marín Álvarez \\ Profesor-investigador de Diseño de la Comunicación Gráfica en la Universidad Autónoma \\ Metropolitana Azcapotzalco, Ciudad de México. México \\ E-mail: marma@azc.uam.mx \\ Mtra. Adriana Acero Gutiérrez \\ Profesora -investigadora de Diseño de la Comunicación Gráfica en la Universidad Autónoma \\ Metropolitana Azcapotzalco, Ciudad de México, México \\ E-mail: adag@azc.uam.mx
}

\author{
Mtra. Nancy Alejandra Noriega Tovilla \\ Profesora-investigadora de Diseño Gráfico en la Benemérita Universidad Autónoma de Puebla, Puebla, \\ México \\ E-mail: nancynotovilla@hotmail.com
}

\begin{abstract}
RESUMEN
Analizamos la relación entre la narrativa y la imagen fotográfica, la interpretación que no es sólo de quien toma la imagen sino también de aquellos que la observan y la recrean. El modo en el cual el positivismo y el historicismo en el siglo XIX marcaron la pauta para la escritura de textos con rigor científico y como la fotografía rompe con estos parámetros. A su vez comparamos la narrativa y la fotografía bajo esta relación biunívoca. La fotografía se incorpora a la narrativa (literaturización) de las relaciones de la vida, pero sólo parcialmente, en aproximaciones algunas de ellas verdaderas y otras tantas imaginarias de quien las aprecia y las relata, siendo una interpretación limitada que le acompañará en diversos momentos, tanto a quien dispara la cámara como a quien la observa y reconstruye.
\end{abstract}

Palabras clave: Narrativa, fotografía, escritura, interpretación, visualización.

\begin{abstract}
We analyze the relationship between narrative and the photographic image, the interpretation that is not only of the one who takes the image but also of those who observe and recreate it. The way in which positivism and historicism in the nineteenth century set the standard for writing texts with scientific rigor and how photography breaks with these parameters. In turn, we compare narrative and photography under this biunivocal relationship. Photography is incorporated into the narrative (literaturization) of the relationships of life, but only partially, in approximations some of them true and others imaginary of the one who appreciates and relates them, being a limited interpretation that will accompany him at various times, both the one who shoots the camera as well as the one who observes and reconstructs it.
\end{abstract}

Keywords: Narrative, photography, writing, interpretation, visualization. 


\section{INTRODUCCIÓN}

A lo largo de la historia de la humanidad se han dado múltiples muestras de la imaginería narrativa por medio de diversos lenguajes. Una de estas manifestaciones es la imagen, la cual, a diferencia de los textos, se percibe e interpreta de acuerdo con el modo de ver de cada observador. En la visualización se dilucidan relaciones intra icónicas que permiten interpretaciones alternativas. Ejemplos de estas son, la lectura realizada de los elementos compositivos como los colores y los contrastes, otra el papel del actante el cual determina la narrativa, que corresponde a un acto de total libertad al ver en la fotografía un caos ordenado y estructurado bajo un ritmo e interés propio.

La fotografía es un fragmento de la realidad, un instante captado a través de la cámara. De acuerdo con Vilém Flusser (2004) esta es un continuum espacio-temporal y lumínico. Suceso, que será percibido más adelante por un observador, el cual la interpretará con base a su alcance, proporcionándole una narrativa particular.

\section{DESCRIPCIÓN DEL MÉTODO}

\subsection{LA NARRATIVA ACOMPAÑANDO AL LENGUAJE}

Sería aventurado precisar el origen del lenguaje. No obstante, algo que ha quedado claro desde el punto de vista científico son, las diversas formas de la comunicación no verbal mediante las cuales dan a conocer cualquier situación. Como aquella necesidad de informar sobre dónde se encuentra un alimento, el expresar algún deseo, el advertir acerca de algún peligro, hacer saber la pertenencia o propiedad, entre otros. Estos actos de comunicación atienden a un aspecto esencial de cooperación.

Por ello, al hablar de la evolución humana se puede pensar en el desarrollo del lenguaje y sus formas de comunicación: verbal y no verbal. Luego sería posible mencionar el acto de narrar, el cual ha acompañado al hombre desde tiempos inmemoriales. Una reflexión para comentar es la concerniente a la diferenciación hecha por Aristóteles, quien conforme a la concepción griega de la tragedia y la epopeya enunció sus partes constitutivas y distinguió dos tipos de narración: la poética y la histórica. Fue durante el siglo XIX que en el historicismo y el positivismo fueron trazados el marco del conocimiento de estricto rigor científico. La escritura también había de ajustarse a las características del método: Introducción, Material y métodos, Resultados y Discusión (IMRYD).

En cuanto al relato, viene de latín relatum, refiere al acto de contar sucesos, acontecimientos o historias, los cuales pueden ser narrados del modo en que acontecieron o de la manera en que se hubiera querido que ocurrieran. Una narrativa puede tratar sucesos de la realidad, ejemplo de este tipo son: la biografía, el informe o la noticia. Pero también contar una historia producida desde la invención como: las fábulas o los cuentos. Esta tesis es sostenida también por María Isabel Castro, quien 
refiere: «El relato es una estructura discursiva, caracterizada por la heterogeneidad narrativa (en el cuerpo de un mismo relato pueden aparecer diferentes tipos de discursos)» (2012: 118).

\subsection{CORRESPONDENCIA ENTRE NARRATIVA Y FOTOGRAFÍA}

En el año 2017 Infortrend, una de las empresas líderes en el almacenamiento de datos en la nube, anunció que en el mundo se captarían alrededor de 1.2 billones de fotografías, con la probabilidad de alcanzar 100000 millones de imágenes más que la cifra anterior. Otro dato señalado fue respecto al medio de captura, y es que en su gran mayoría estas se han de tomar mediante el uso de dispositivos móviles. Acorde con estos datos, se puede estimar que esta generación ha de alcanzar el mayor número de registros fotográficos en la historia. La incertidumbre radica sobre la utilidad de la mayoría de esas fotografías y dónde quedará almacenada tal producción.

Pocos se preguntarán sobre la razón de captar una fotografía. Sin embargo, para algunos fotógrafos el motivo se encuentra al considerarla como una máquina del tiempo. Ya que, es una forma de conservar los recuerdos y las experiencias. Sin duda, este acto debe producir más de alguna satisfacción. Definitivamente, el acto de fotografiar puede deberse a una infinidad de motivos: deber, placer, deseo, poder... Como sostuvo Susan Sontag (1996:14): «Fotografiar es apropiarse de lo fotografiado. Significa establecer con el mundo una relación determinada que sabe a conocimiento y por lo tanto a poder.»

Hasta este punto se ha reflexionado sobre la narrativa y la fotografía por separado. Ahora, es momento de plantear las siguientes preguntas: ¿en qué momento de la tradición fotográfica se tomó consciencia de la narrativa en la imagen?, ¿se realizan historias con una narrativa o es la historia la que se retrata?, una vez fotografiado un instante de la vida ¿es posible que a través de este se dé cuenta de lo antes sucedido?, ¿el observador puede adentrarse más allá de lo visible en la imagen?

Para contestar estas preguntas se habrá de referir algunos puntos claves que dejan en claro la correspondencia entre narrativa y fotografía. Para ello, habrá de situarse en la ciudad de París en el año de 1840, y hacer referencia a Hippolyte Bayard, considerado junto con Joseph Nicéphore Niépce, Louis Daguerre y William Fox Talbot, precursores de la fotografía. Bayard realizó un sinnúmero de dibujos fotogénicos (se recomienda revisar además el término de positivo directo), costeados con sus medios. Otra de las aportaciones a mencionar son sus diversas fórmulas químicas para el procesado. Cabe aclarar que estos avances no tienen relación alguna con los trabajos de Talbot o de Daguerre, salvo la lucha por llegar a ser el primero en presentar su invento ante la Sociedad Francesa de Fotografía.

Posteriormente a la consecución del dibujo fotogénico, Bayard obtuvo imágenes en negativo y positivo, aunque la calidad lograda fue considerada menor a aquellas producidas mediante el daguerrotipo. Después se presentó en la Academia de Ciencias y Artes Francesa para que se le 
reconocieran sus adelantos y aportaciones a la fotografía. Aunque, la respuesta que obtuvo sobre su proceso fue que había sido superado por el daguerrotipo. A causa de esto, Bayard realizó un acto de oposición contra lo que él consideró un atropello por parte de los miembros de la Academia, este acto refiere al envío de una serie de tres fotografías, aquí se muestra solo una de las tres imágenes pertenecientes a esta serie (ver la figura 1):

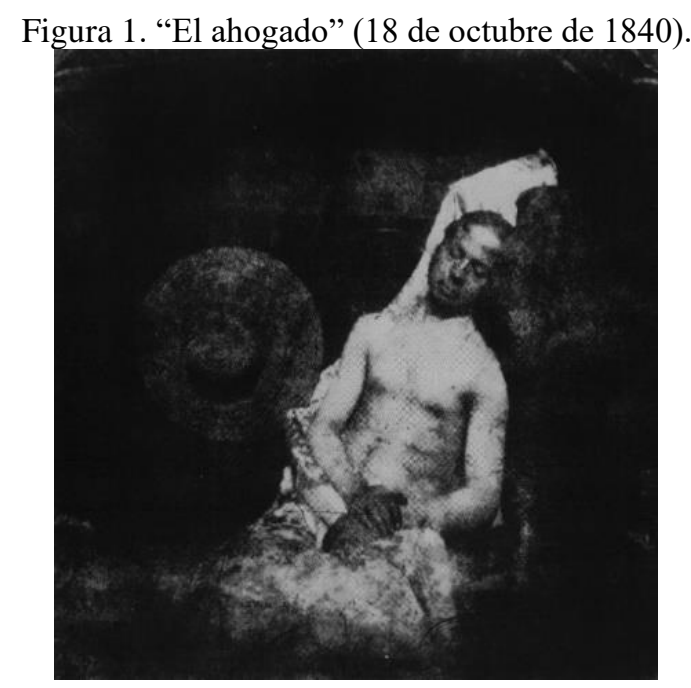

Batchen, G. Autorretrato de Hippolyte Bayard en un aparente estado post mortem, envuelto en una sábana y caracterizado de un cadáver en avanzado estado de descomposición. Arder en deseos, la concepción de la fotografía. 2004.

A pesar de haber perdido la paternidad de la invención fotográfica, Hippolyte Bayard logró otras aportaciones con la imagen de El ahogado, la que cimbró a la sociedad francesa en su momento, causando una gran confusión y el debate sobre su legitimidad. Se meditará brevemente, algunas de las contribuciones que versan sobre esta imagen:

- Se considera la primera fotografía mentirosa del medio, ya que logró el efecto de engaño en el observador.

- Se puede hablar de una narrativa fotográfica que registra el suicidio de un hombre.

- Su realización presupone la concepción de un diseño fotográfico (idea no existente hasta ese momento) convertida posteriormente en imagen. Se puede apreciar en ella una composición fotográfica: con la disposición de un sombrero sobre un aparente muro, un maquillaje en las manos que logra un aspecto cadavérico y el recurso mortuorio de una sábana.

- Es la primera fotografía que retrata a un hombre posteriormente de que este cometiera suicidio.

- Es uno de los primeros autorretratos.

- Se advierte como el primer desnudo fotográfico. 
- Es la primera imagen de ficción.

Recapitulando, este autorretrato de Bayard abrió la posibilidad hacia la concepción de otro tipo de fotografía, como por ejemplo: la fotografía científica, la fotografía forense, y desde luego aquella cuyo tema nos ocupa, la narrativa fotográfica. Dado que, dejó registro de que una imagen puede ser texto, epígrafe, evidencia o simulación.

\subsection{UNA IMAGEN VALE MÁS QUE MIL PALABRAS}

A través de la historia, la imagen ha jugado el papel de transmitir conocimiento. Ha formado parte de un fenómeno de emisión y recepción del pensamiento íntegro y autónomo. Su profusión se ha incrementado (tanto la imagen fija como la imagen en movimiento) y con ella la dificultad de comprender cada uno de los mensajes. Esto es claro al tomar en cuenta que, interpretar el lenguaje visual conlleva descubrir diferentes significaciones. Ya que, el proceso de interpretar una narrativa visual no resulta una tarea sencilla.

La representación de lo visual está ligada al ser humano, como puede confrontarse a través del tiempo y del espacio. Esta capacidad es la base para la producción de la imagen, realización que dará referencia a un tiempo-espacio particular. Por lo que, para capturar una determinada historia se requiere del entendimiento de lo percibido y para su interpretación del acercamiento a la obra y de igual manera una aproximación al autor. Esto es, entender las características y los procesos a través de los cuales fue desarrollada. Asimismo, es importante tomar en cuenta las diferentes tipologías gráficas y la heterogeneidad de realizadores. Porque es posible asimismo hablar de una sintaxis social, histórica y geográfica específica, la cual establece una disposición común, también se ha de considerar el propósito del realizador.

Por otro lado, al considerar la expresión «una imagen vale más que mil palabras», tendría que aclararse un posible sentido. Ya que, cada imagen podría ser significativa en más de mil formas distintas, dado que se podrían hacer tantas valoraciones según cada observador. Por lo que, el sentido señalado figura más hacia la multiplicidad de interpretaciones. Según Kurtz «La imagen gráfica no determina una equivalencia con mil palabras, sino que determina una ambigüedad por ser tantas las combinaciones de palabras que pudiera sustituir» (1994: 3). Desde esta perspectiva, se puede entender que la imagen es un signo que cada observador interpretará de acuerdo con su marco cultural.

\subsection{LA CREACIÓN DE IMÁGENES FOTOGRÁFICAS Y SU NARRATIVA}

Los seres humanos somos capaces de producir y decodificar imágenes. Estas poseen un significado al representar la realidad en cuatro dimensiones (largo, ancho, profundo y tiempo) y una 
codificación de sucesos. En otros términos, cuando se percibe lo visual, las dimensiones espaciales temporales, se reconstituyen de modo constante en cada individuo. Sin embargo, es la propia estructura de la imagen la que sirve en la interpretación del observador en consonancia, además, de su situación: cultural, geográfica y anímica, por citar algunos de los factores.

De manera que, el significado de una imagen y su propia narrativa se representa en un doble plano: el primero, es la creación del sentido referencial, es decir lo que denota; y el segundo, aquella interpretación y relatos únicos que descubre cada observador, lo que connota. Por tanto, las imágenes pueden ser interpretadas a partir de lo que denotan (ver figura 2).

Figura 2. Proceso de percepción de una imagen

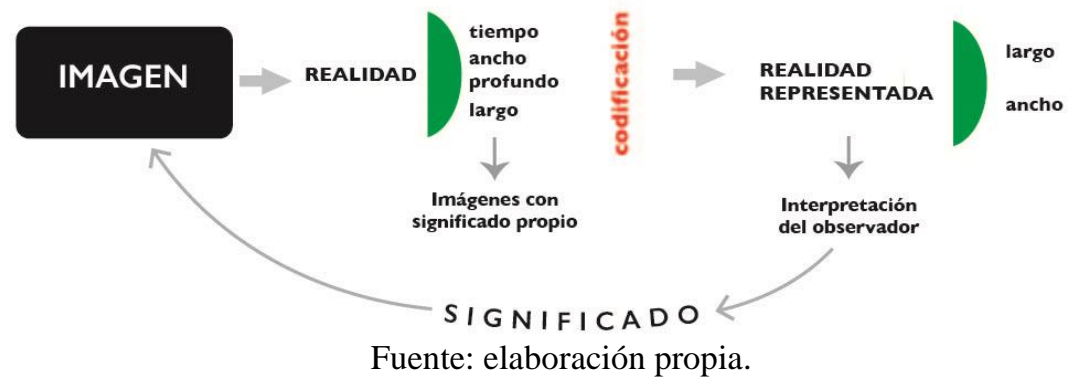

$\mathrm{Al}$ observar una imagen fotográfica con detenimiento, se sabe puede representar algún tiempo pasado, una narrativa sentimental o aludir a la muerte, (Roland Barthes en La cámara lúcida). Es mediante la fotografía que el hombre transmuta el pasado en una urdimbre de separaciones morales independientes de su contexto. Por otra parte, los juicios son construcciones temporales de quien hace la visión-narración sobre una fotografía.

Ahora bien, una observación aparte sobre la objetividad en la imagen es aquella que los fotorreporteros señalan: pues argumentan que en su gran mayoría sus imágenes revelan un significado invariable, ya que muestran la verdad. En principio dicha tesis es válida debido a que los signos de la imagen están en un determinado contexto. Sin embargo, al cambiar de contexto, tanto el significado como la narrativa se transforman. No se puede dejar de apuntar que, al emplear los originales estos sufren transformaciones por parte de otros en el transcurso del tiempo. Sobre todo, cuando la imagen es absorbida en el campo artístico, y donde es posible captar casi cualquier tipo de fotografía o bien derivarla en otra obra.

Se propone el análisis de dos pares de imágenes consideradas a partir de sus valores históricos, estéticos y periodísticos. En el primer par, se muestra por un lado el izamiento de la bandera norteamericana a cargo de los marines en Iwo Jima en el año de 1945 y la transformación realizada por Ed Freeman en el año 2015. En el segundo par, se muestra la fotografía de Nick Ut, La niña quemada 
por el napalm en la guerra de Vietnam en el año de 1972 y la transformación en grafiti realizada por Banksy:

Figura 3. Alzando la bandera en Iwo Jima

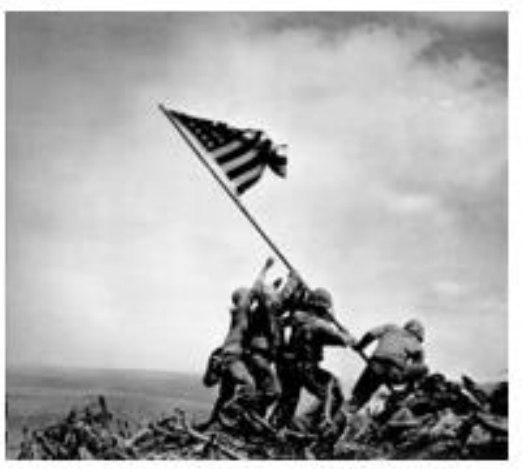

Fuente: Rosenthal, 1945.

Figura 5. Niña quemada por napalm

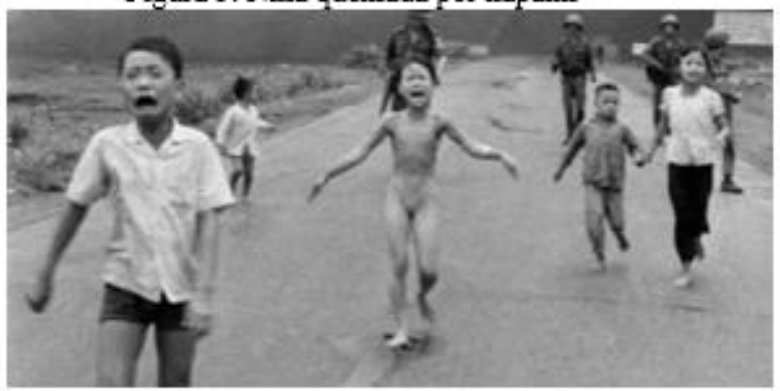

Fuente: Nick Ut. 1972. Ap Images s.f.
Figura 4. Getty Images

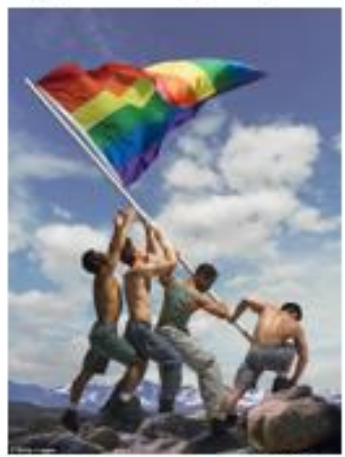

Fuente: Freeman, 2015.

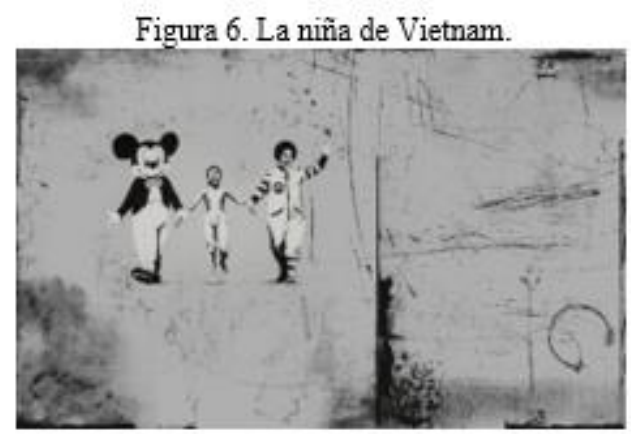

Fuente: Travesias, 2016. La niña de Vietnam, Bansky.

La narrativa de estas imágenes obedece a sus respectivos momentos históricos, políticos, sociales y económicos (tal y como se ha aclarado); corresponde a cada observador percibir, interpretar y narrar cada imagen.

\section{CONCLUSIONES}

La verdadera fuerza narrativa de una imagen fotográfica radica esencialmente en conservar esos instantes que bajo las circunstancias del discurrir del tiempo serán reemplazados irremediablemente por otros momentos. Es el tiempo detenido de la imagen, el cual se mostrará algo bello o la incapacidad para participar de la verdad.

A diferencia de un video o una película cinematográfica, en el momento de disparar una fotografía se captura el instante. Un registro de la vida y que al verlo vale por mucho analizarlo, recrearlo, deconstruirlo y narrarlo nuevamente. Por tanto, se puede decir que la fotografía tiene dos puntos de vista (dos narraciones): quien la captura y la de cada observador, quien la mira por deleite y hace su propia narración, concentrándose por tanto en una experiencia en lo particular. 
De este modo, entendemos que los textos pueden contradecir lo que vemos con el cerebro a través de los ojos. Sin embargo, ningún texto puede limitar o asegurar el significado de una imagen fotográfica perpetuamente, pues variará conforme a la evolución histórica de los acontecimientos y porque esta jamás hablará. La narrativa es esa voz de la cual carece la fotografía. La narrativa es una interpretación limitada que le acompañará en diversos momentos. En la fotografía se incorpora, por tanto, la narrativa (literaturización) de las relaciones de la vida. Pero, solo parcialmente, en aproximaciones algunas de ellas verdaderas y otras tantas imaginarias de quien las aprecia y las relata. La narrativa en la fotografía no es de ninguna manera única y autónoma, es más bien heterogénea. Si bien, los elementos técnicos de la imagen son importantes, su derivación narrativa es cultural. Por ende, es lo que hacemos y decimos con ella. La fotografía es proxémica, ya que nos acerca al acontecimiento, conserva un tiempo que es posible reinterpretar. Es incluso, mucho más inmediato que un texto pues la información que proporciona este es más lento con respecto a la imagen, debido a las reglas de la sintaxis y las estructuras de la lectura. 


\section{REFERENCIAS}

- $\quad$ AP Images. (s. f.). Niña quemada por napalm, Nick Ut, 1972. [Imagen]. Disponible en http://www.apimages.com/Collection/Landing/Photographer-Nick-Ut-The-Napalm-Girl/ebfc0a860aa946ba9e77eb786d46207e

- $\quad$ AP News. (2017). Alzando la bandera en Iwo Jima, Rosenthal, 1945. [Imagen]. Disponible en https://www.apnews.com/f00e1181d57a414a848ac96b772839fd

- $\quad$ Barthes, R. (2003) La cámara lúcida. Barcelona: Paidos comunicación.

- $\quad$ Batchen, G. (2004). Arder en deseos, la concepción de la fotografía. Barcelona, Gustavo Gili.

- $\quad$ Castro Díaz, M. (2012). Estrategias narrativas en la fotografía actual: el fotodrama como tipología artística. [Tesis doctoral]. España: Universidad Complutense. Disponible en https://eprints.ucm.es/16050/1/T33511.pdf

- Ed Freeman Photography. (2015). Pride. [Imagen]. Disponible en: https://www.edfreeman.com/products/gay-pride

- $\quad$ Flusser, V. (2004). Hacia una filosofía de la fotografía. México, D.F.: Trillas.

- Kurtz, G. (1994). La fotografía como instrumento para la historia. Consejería de Educación de la Embajada de España en el Principado de Andorra. Ministerio de Educación y Ciencia. Cuadernos de Ciencias Sociales de Andorra .3.

- $\quad$ Sontag, S. (1996). Sobre la fotografía. Barcelona: Edhasa. 